\title{
Reação de genótipos de soja ao alumínio em hidroponia e no solo(1)
}

\begin{abstract}
Luiz Augusto Copati Souza(2)
Resumo - O objetivo deste trabalho foi avaliar os genótipos de soja BR86-5974, BR86-7396, Dourados, Doko RC, EMGOPA 305, IAC-9, BR-9 (Savana), UFV-1, UFV-9 e UFV Araguaia em relação à tolerância ao alumínio $(\mathrm{Al})$ em hidroponia e em solo. Na solução com $\mathrm{Al}$ foi medido o comprimento radicular. Em solo com $49 \%$ de saturação de $\mathrm{Al}$ avaliou-se área foliar, altura de planta, altura de inserção da primeira vagem, produção de matéria seca, produção de grãos e índice de colheita. Os genótipos BR86-7396 e IAC-9 são os de maior tolerância ao Al, e UFV-1 mostrou o pior desempenho. Houve correlação significativa entre alongamento radicular e produção de grãos $(r=0,705)$, área foliar $(\mathrm{r}=0,645)$ e produção de matéria seca $(\mathrm{r}=0,634)$. Isto indica que experimentos em hidroponia e solo são igualmente eficientes na seleção de soja tolerante ao alumínio. A variabilidade detectada sugere que o conjunto de genótipos de soja possui ampla variabilidade genética, o que é desejável em programas de melhoramento com o objetivo de elevar estabilidade de produção no Cerrado.
\end{abstract}

Termos para indexação: Glycine max, absorção de nutrientes, elementos metálicos, variação genética.

\section{Soybean genotypes reaction to aluminium in hydroponics and soil}

\begin{abstract}
The soybean genotypes BR86-5974, BR86-7396, Dourados, Doko RC, EMGOPA 305, IAC-9, BR-9 (Savana), UFV-1, UFV-9 e UFV Araguaia were evaluated for Al tolerance in simpleshort term nutrient solution and in soil. Root elongation was measured in the nutrient solution, and the following agronomic characters were measured for the soil evaluation of tolerance: leaf area, plant height, first pod height, dry matter, grain yield and harvest index. The soil was partly amended with lime to leave $49 \% \mathrm{Al}$ saturation. The most tolerant genotypes in both experiments were BR86-7396 and IAC-9; UFV-1 was shown to be the most intolerant. A positive correlation coefficient of root elongation and field parameters of grain $(r=0.705)$, dry matter yield $(r=0.634)$ and leaf area $(r=0.645)$ indicate that short term hydroponics and field experiments are equally effective in screening Al-tolerant soybean genotypes. The detected genetic variability among the genotypes demonstrate that it can efficiently be used in breeding programmes to improve yield stability in the Brazilian Savannahs (Cerrado).
\end{abstract}

Index terms: Glycine max, nutrient uptake, metallic elements, genetic variation.

\section{Introdução}

A identificação de tolerância ao $\mathrm{Al}$ em soja por testes de hidroponia somente apresenta importância quando há correspondência com a avaliação de campo. Diversos trabalhos com hidroponia procuraram estabelecer ligação entre os testes de campo e os de

(1)Aceito para publicação em 2 de abril de 2001.

Extraído da Dissertação de Mestrado apresentada pelo autor à Universidade de Brasília (UnB), Brasília, DF.

${ }^{(2)} \mathrm{QE}$ 19, Conj. L, Casa 11, CEP 71050-123 Guará II, DF. E-mail: gutocopati@yahoo.com laboratório. Ainda que resultados obtidos nesses dois métodos nem sempre se correlacionem, existem relatos em que ambos são igualmente eficientes na discriminação de genótipos tolerantes ao Al (Spehar, 1989; Campbell \& Carter Junior, 1990; Vicente, 1993).

O cultivo em solução nutritiva é de grande interesse para a seleção de plantas ou em estudos específicos de fisiologia e nutrição, graças à facilidade que esse método oferece na avaliação da parte aérea e do sistema radicular (Delhaize \& Ryan, 1995). Além de permitir melhor controle das variáveis não experimentais, o que aumenta a precisão dos testes (Spehar, 
1994b), o método apresenta como vantagem a rapidez e a não-destrutividade, o que possibilita cultivar as plântulas selecionadas para avanço de geração e futuro teste da progênie (Spehar \& Makita, 1994).

O Al afeta o crescimento das raízes, especificamente do ápice radicular (Kochian, 1995). O eixo principal tem seu alongamento inibido, as raízes ficam grossas, com coloração castanha, quebradiças e ocasionalmente com manchas necróticas (Bennet \& Breen, 1991; Machado, 1997). As regiões meristemáticas das raízes primárias e laterais desorganizam-se a ponto de tornar difícil a distinção entre coifa e elementos vasculares (Foy, 1988). O Al atua indiretamente no processo metabólico associado com a divisão celular, através da inibição do processo de crescimento, e atua também diretamente na divisão celular, interferindo na replicação de DNA durante a interfase (McQuattie \& Schier, 1990).

A avaliação em campo é mais utilizada pelos melhoristas, por possibilitar adaptação ao ambiente e a seleção baseada em características agronômicas de interesse como produtividade e ciclo. No entanto, pode apresentar o inconveniente de reunir grande número de variáveis não controláveis (Furlani \& Clark, 1981). Para que a avaliação em campo seja eficiente, o solo deve apresentar teores uniformemente altos de $\mathrm{Al}$, e baixos de $\mathrm{Ca}, \mathrm{Mg}, \mathrm{P}$ e $\mathrm{Mn}$, para que os efeitos de Al não sejam mascarados. Uma grande dificuldade nesses experimentos é determinar a saturação de $\mathrm{Al}$ a que os genótipos serão submetidos. A saturação de Al ideal para o cultivo de soja deve ser inferior a 5\% (Embrapa, 1998). Spehar (1994a), em solo com $29 \%$ de saturação de Al na camada arável e $33 \%$ na camada subsuperficial, encontrou diferenças entre genótipos quanto à produtividade de grãos.

A quantidade de água no solo deve ser controlada, porque pequenos estresses hídricos acentuam a toxidez de Al e facilitam a identificação das diferenças entre genótipos (Goldman et al., 1989). Os estudos do sistema radicular têm por objetivo determinar os efeitos do $\mathrm{Al}$ sobre o alongamento e divisão das células, enquanto os estudos em solo refletem o efeito continuado do Al sobre a parte aérea, raízes e absorção de nutrientes. Nesses últimos, a avaliação de tolerância é obtida pela produção de grãos e matéria seca.
Garland et al. (1990) encontraram correlação entre o comprimento das raízes de plântulas de soja cultivadas em hidroponia e o peso seco das plantas no solo ao elevarem o número de indivíduos por repetição. Spehar (1989), ao avaliar híbridos da geração $F_{1}$ procedentes de nove genótipos de soja, selecionados previamente em experimento de campo, observou correlação significativa entre os testes hidropônicos e os de campo.

O objetivo deste trabalho foi avaliar genótipos de soja quanto a sua tolerância ao alumínio em hidroponia e em campo.

\section{Material e Métodos}

Em hidroponia foram avaliados os genótipos BR86-5974, BR86-7396, Dourados, Doko RC, EMGOPA 305, IAC-9, BR-9 (Savana), UFV-1, UFV-9 e UFV Araguaia quanto à tolerância ao $\mathrm{Al}$ em solução nutritiva. Sua escolha baseou-se em características agronômicas desejáveis e pela sua resposta ao $\mathrm{Al}$ em outros experimentos (Spehar \& Makita, 1994).

Para cada genótipo separaram-se, ao acaso, dois lotes de 60 sementes que foram enroladas em papel de filtro embebido em água para germinar. Com o objetivo de produzir radículas sem dobras, os roletes foram dispostos verticalmente dentro de bécheres de $1.000 \mathrm{~mL}$ com $100 \mathrm{~mL}$ de água. Os recipientes foram envolvidos por filme de plástico para evitar perda de umidade, e colocados em um germinador sem iluminação e à temperatura de $25 \pm 1^{\circ} \mathrm{C}$. Após 96 horas, os roletes foram retirados do germinador, e as plântulas foram classificadas de acordo com o tamanho das radículas. Desprezaram-se as de comprimento inferior a $25 \mathrm{~mm}$ ou superior a $35 \mathrm{~mm}$. Mediu-se o comprimento radicular inicial de 28 plântulas de cada um dos genótipos, e estas foram separadas em quatro grupos que foram fixados em suportes de plástico flutuantes sobre água destilada.

Terminada a preparação das plantas, os suportes foram transferidos para tanques de plástico de $256 \mathrm{~mm} \mathrm{x}$ $316 \mathrm{~mm} \times 115 \mathrm{~mm}$, contendo $5,0 \mathrm{~L}$ da solução de $2,0 \mathrm{mg} / \mathrm{L}$ de $\mathrm{Al}$ na forma de $\mathrm{Al}_{2}\left(\mathrm{SO}_{4}\right) \cdot 16 \mathrm{H}_{2} \mathrm{O}$ mais $160,0 \mathrm{mg} / \mathrm{L}$ de $\mathrm{Ca}$ na forma de $\mathrm{Ca}\left(\mathrm{NO}_{3}\right)_{2}$. Adicionou-se o íon $\mathrm{Ca}$, para evitar a desestabilização do $\mathrm{pH}$, acelerar o alongamento radicular e, conseqüentemente, aumentar a absorção de Al, conforme citado por Garland et al. (1990). $\mathrm{O}$ pH foi corrigido para 4,0 com ácido sulfúrico $\left(\mathrm{H}_{2} \mathrm{SO}_{4}\right)$ $1 \mathrm{~N}$ a cada 24 horas, porque nesse nível de acidez aumenta-se a disponibilidade de $\mathrm{Al}^{3+}$, que é a forma tóxica (Kinraide, 1991). 
Os tanques foram cobertos por filme de plástico, para evitar evaporação da água, e em seguida, levados à câmara de crescimento iluminada com 550 e $635 \mathrm{~nm}$, à temperatura de $25 \pm 1^{\circ} \mathrm{C}$, e umidade relativa próxima a $75 \%$. Para oxigenação e circulação da solução, tubos ligados a um compressor foram instalados no fundo de cada tanque. Após 48 horas de exposição a essas condições, mediu-se o comprimento final das raízes, do qual foi subtraído o comprimento inicial para determinação do alongamento radicular.

O delineamento experimental foi o inteiramente casualizado, com quatro repetições. As médias foram comparadas pelo teste de Duncan a 5\% de probabilidade.

A avaliação em solo foi realizada num Latossolo Vermelho-Escuro, anteriormente sob vegetação de Cerrado, em Planaltina, DF $\left(15^{\circ} 35^{\prime} 30^{\prime \prime} \mathrm{S}\right.$ e $\left.47^{\circ} 42^{\prime} 30^{\prime \prime} \mathrm{W}\right)$, com a seguinte granulometria: $350 \mathrm{~g} \mathrm{~kg}^{-1}$ de areia, $190 \mathrm{~g} \mathrm{~kg}^{-1} \mathrm{de}$ silte e $460 \mathrm{~g} \mathrm{~kg}^{-1}$ de argila. Antes da instalação do experimento conduziu-se um ensaio em branco para avaliar a uniformidade da área. Utilizou-se a variedade BR-9 (Savana), por responder às possíveis diferenças na fertilidade. Para confirmar a uniformidade do solo, realizaramse análises químicas nas profundidades de 0-20 e de 20-40 cm. As características químicas do solo antes da aplicação do calcário e dos fertilizantes são apresentadas na Tabela 1.

Aplicaram-se $1.000 \mathrm{~kg} \mathrm{ha}^{-1}$ de calcário (PRNT 100\%) dois meses antes da semeadura, para que a saturação de $\mathrm{Al}$ atingisse valores próximos a 50\% (Hanson \& Kamprath, 1979; Spehar, 1994a). Cinco dias antes da semeadura foram aplicados $150 \mathrm{~kg} \mathrm{ha}^{-1}$ de $\mathrm{P}_{2} \mathrm{O}_{5}$ (superfosfato triplo),
$120 \mathrm{~kg} \mathrm{ha}^{-1}$ de $\mathrm{K}_{2} \mathrm{O}$ (cloreto de potássio), $2 \mathrm{~kg} \mathrm{ha}^{-1}$ de B (bórax), $5 \mathrm{~kg} \mathrm{ha}^{-1}$ de $\mathrm{Zn}$ (sulfato de zinco), $2 \mathrm{~kg} \mathrm{ha}^{-1} \mathrm{de}$ $\mathrm{Cu}$ (sulfato de cobre), $250 \mathrm{mg} \mathrm{ha}^{-1}$ de Mo (molibdato de sódio), $50 \mathrm{~g} \mathrm{ha}^{-1}$ de Co (sulfato de cobalto), e $30 \mathrm{~kg} \mathrm{ha}^{-1}$ de S (gesso agrícola) conforme Souza et al. (1996). O calcário e os fertilizantes foram incorporados no solo com o auxílio de enxada rotativa (rotavator). Os resultados da análise química do solo após a aplicação do calcário e dos fertilizantes são mostrados na Tabela 1 .

A semeadura foi realizada no dia 20 de dezembro de 1998 e utilizaram-se parcelas em linha de $50 \mathrm{~cm}$ de comprimento onde foram colocadas 30 sementes. A distância entre fileiras foi de $80 \mathrm{~cm}$, e entre parcelas na mesma fileira, 70 cm (Spehar, 1998). Para deixar uma população máxima de 14 indivíduos por parcela, foi feito um desbaste, 15 dias após a emergência das plantas.

Após 50 dias da instalação do experimento, a sétima e/ou oitava folhas, contadas de baixo para cima, começando da primeira trifoliolada, foram retiradas para determinação da área foliar (Spehar, 1996). Ao final da maturação, as plantas foram cortadas rente ao solo, e coletaram-se dados dos seguintes parâmetros: altura da planta; altura de inserção da vagem inferior; produção de matéria seca; produção de grãos; índice de colheita e duração do ciclo, em dias.

Durante o ciclo da cultura ocorreram aproximadamente $490 \mathrm{~mm}$ de precipitação pluvial. Entre o dia 15 de janeiro e o dia 17 de fevereiro choveu menos que $40 \mathrm{~mm}$. A maior chuva foi de $15 \mathrm{~mm}$, no dia 29 de janeiro. A evapotranspiração, no mesmo período, medida em tanque classe A, foi superior a $190 \mathrm{~mm}$. Para que esse estresse

Tabela 1. Análise química do solo da área experimental após ensaio em branco com soja cultivar BR-9 (Savana) e após aplicação do calcário e dos fertilizantes.

\begin{tabular}{lccccc}
\hline Variável & \multicolumn{2}{c}{ Após ensaio em branco } & & \multicolumn{2}{c}{ Após aplicação dos corretivos } \\
\cline { 2 - 3 } \cline { 5 - 5 } & $0-20 \mathrm{~cm}$ & $20-40 \mathrm{~cm}$ & & $0-20 \mathrm{~cm}$ & $20-40 \mathrm{~cm}$ \\
\hline $\mathrm{pH}\left(\mathrm{H}_{2} \mathrm{O}\right)$ & 4,34 & 1,38 & 4,94 & 4,49 \\
$\mathrm{Al}\left(\mathrm{cmol}_{\mathrm{c}} \mathrm{dm}^{-3}\right)$ & 1,64 & & 1,15 & 1,27 \\
$\mathrm{H}+\mathrm{Al}\left(\mathrm{cmol}_{\mathrm{c}} \mathrm{dm}^{-3}\right)$ & 8,26 & 7,18 & & 7,60 & 7,05 \\
$\mathrm{Ca}\left(\mathrm{cmol}_{\mathrm{c}} \mathrm{dm}^{-3}\right)$ & 0,30 & 0,15 & & 0,69 & 0,23 \\
$\mathrm{Mg}\left(\mathrm{cmol}_{\mathrm{c}} \mathrm{dm}^{-3}\right)$ & 0,17 & 0,06 & & 0,38 & 0,21 \\
$\mathrm{MO}(\%)$ & 2,84 & 2,22 & & 2,94 & 2,43 \\
$\mathrm{P}(\mathrm{mg} / \mathrm{L})$ & 1,04 & 0,64 & & 3,13 & 1,14 \\
$\mathrm{Cu}(\mathrm{mg} / \mathrm{L})$ & 0,85 & 0,80 & & 1,10 & 0,95 \\
$\mathrm{Fe}(\mathrm{mg} / \mathrm{L})$ & 97,50 & 98,50 & & 85,00 & 78,00 \\
$\mathrm{Mn}(\mathrm{mg} / \mathrm{L})$ & 4,85 & 4,35 & & 4,60 & 3,75 \\
$\mathrm{Zn}(\mathrm{mg} / \mathrm{L})$ & 0,45 & 0,40 & & 2,50 & 2,15 \\
$\mathrm{~K}(\mathrm{mg} / \mathrm{L})$ & 116,50 & 84,00 & & 160,50 & 118,50 \\
\hline
\end{tabular}


hídrico não comprometesse o desenvolvimento das plantas, foram feitas quatro irrigações de aproximadamente 20 mm cada uma.

O delineamento experimental adotado foi o inteiramente casualizado, com dez repetições. A análise multivariada foi feita a partir das médias das dez parcelas, exceto quanto ao alongamento radicular, em que os valores foram obtidos pela média das quatro repetições. Para avaliar o grau de diversidade da coleção, utilizou-se a análise de componentes principais; e para obter os grupos homogêneos de genótipos utilizou-se o método de classificação dos vizinhos mais próximos, referentes aos dois primeiros componentes principais (Cruz \& Regazzi, 1994). Todas as análises foram realizadas por meio do pacote estatístico LISA (Francillion et al., 1987).

\section{Resultados e Discussão}

A linhagem BR86-7396 e a cultivar IAC-9, seguidos de Doko RC e BR-9 (Savana) são os genótipos que têm maior tolerância ao Al, e a cultivar UFV-1 é a que se mostrou mais intolerante (Tabela 2). Esses resultados são semelhantes aos de Spehar (1994a) e Spehar \& Makita (1994).

A diferença entre os genótipos pode ser explicada pela diferença de vigor entre as sementes e pela existência de diferentes níveis de tolerância ao alumínio. $\mathrm{O}$ efeito de vigor foi controlado ao máximo ao se escolherem plântulas com comprimentos de raízes semelhantes às do início do teste. Plântulas conside-

Tabela 2. Alongamento radicular médio, máximo e mínimo de genótipos de soja expostos a $2,0 \mathrm{mg} / \mathrm{L}$ de $\mathrm{Al}+160,0 \mathrm{mg} / \mathrm{L}$ de Ca por 48 horas.

\begin{tabular}{lccc}
\hline \multirow{2}{*}{ Genótipo } & \multicolumn{3}{c}{ Alongamento $(\mathrm{mm})$} \\
\cline { 2 - 4 } & Médio $^{(1)}$ & Máximo & Mínimo \\
\hline BR86-7396 & $25,6 \mathrm{a}$ & 52,0 & 4,0 \\
IAC-9 & $25,2 \mathrm{a}$ & 43,0 & 2,0 \\
Doko RC & $19,3 \mathrm{~b}$ & 32,0 & 5,0 \\
BR-9 (Savana) & $19,3 \mathrm{~b}$ & 39,0 & 5,0 \\
BR86-5974 & $17,7 \mathrm{bc}$ & 32,0 & 5,0 \\
EMGOPA-305 & $15,0 \mathrm{bcd}$ & 30,0 & 1,0 \\
UFV-9 & $13,1 \mathrm{cde}$ & 19,0 & 7,0 \\
UFV Araguaia & $11,1 \mathrm{de}$ & 18,0 & 2,0 \\
Dourados & $9,4 \mathrm{de}$ & 22,0 & 2,0 \\
UFV-1 & $7,5 \mathrm{e}$ & 16,0 & 1,0 \\
\hline
\end{tabular}

${ }^{(1)}$ Médias seguidas pela mesma letra não diferem entre si (Duncan, $\mathrm{p} \leq 0,05$ ); o coeficiente de variação foi $45,43 \%$. radas intolerantes tiveram menores alongamentos, apresentaram o eixo principal e as raízes secundárias com maior diâmetro e desorganização da região meristemática das raízes primárias, o que significa sintomas claros de toxidez de $\mathrm{Al}$ (Bennet \& Breen, 1991; Kochian, 1995; Machado, 1997). Assim, infere-se que a segunda hipótese seja a que mais tenha contribuído para a dispersão dos genótipos.

Durante seu processo de adaptação ao cerrado, a soja não foi selecionada especificamente em relação à tolerância ao alumínio. Por ser esta uma característica poligênica com efeitos predominantemente aditivos (Spehar \& Galwey, 1995), surge a possibilidade de que uma variedade possa ser composta de linhagens com diferentes níveis de tolerância ao Al. Essa hipótese pode explicar a grande amplitude observada entre o alongamento máximo e mínimo em um único genótipo.

Ao se calcular os coeficientes da correlação simples de Pearson, observa-se a existência de correlação significativa entre alongamento radicular e produção de grãos $(\mathrm{r}=0,705, \mathrm{p} \leq 0,05)$, área foliar $(\mathrm{r}=0,645, \mathrm{p} \leq 0,05)$, e produção de matéria seca $(r=0,634, p \leq 0,05)$. Pode-se dizer que na seleção em hidroponia obtêm-se genótipos mais tolerantes ao Al. Spehar (1989), Campbell \& Carter Junior (1990) e Vicente (1993) também citam essa possibilidade.

Fez-se análise de componentes principais, e verificou-se que os dois primeiros componentes representam $85,57 \%$ da variação contida na matriz dos dados. Foram estabelecidos quatro grupos de similaridade, pelo método dos vizinhos mais próximos, que explicou 78,20\% da variação total. Com relação às médias das variáveis de cada grupo de similaridade, houve variabilidade em todos os caracteres (Tabela 3), o que demonstra que o conjunto de genótipos possui ampla variabilidade genética das características consideradas, e esta pode ser explorada em programas de melhoramento que visem à maior estabilidade de produção dessa cultura.

As Figuras 1 e 2 representam, respectivamente, a intensidade e a direção dos vetores das variáveis e a dispersão dos genótipos em relação aos dois primeiros componentes principais. Os genótipos que tiveram maior produção de grãos e de matéria seca (grupo 3) destacam-se pelo grande alongamento radicular em hidroponia. O grupo 1 é aquele que tem genótipos 
Tabela 3. Médias das variáveis para os grupos de similaridade de 10 genótipos de soja, agrupados por ciclo.

\begin{tabular}{lrrrr}
\hline Variável & \multicolumn{4}{c}{ Grupo de similaridade } \\
\cline { 2 - 4 } & \multicolumn{1}{c}{1} & \multicolumn{1}{c}{3} & \multicolumn{1}{c}{4} \\
\hline Alongamento radicular (mm) & 12,37 & 25,65 & 19,30 & 18,18 \\
Altura da planta (cm) & 48,72 & 45,71 & 66,87 & 56,36 \\
Área foliar (cm Ć $_{\text {Índice de colheita }}$ & 471,50 & 571,00 & 556,00 & 512,00 \\
Inserção da primeira vagem (cm) & 49,05 & 53,70 & 46,52 & 48,04 \\
Produção de matéria seca (g) & 9,05 & 9,57 & 14,03 & 10,74 \\
Produção de grãos (g) & 15,23 & 17,38 & 21,14 & 20,27 \\
\hline
\end{tabular}

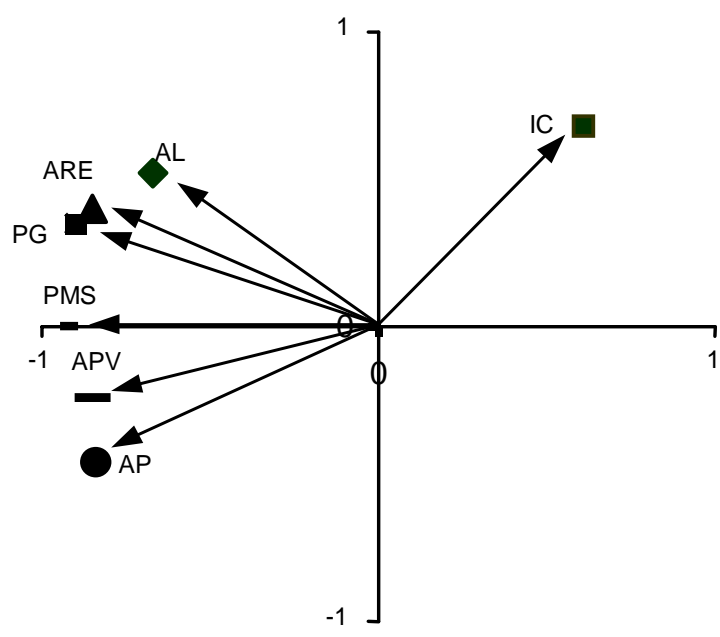

Figura 1. Representação gráfica dos vetores área foliar (ARE), altura das plantas (AP), altura da inserção da primeira vagem (APV), produção de matéria seca (PMS), produção de grãos (PG), índice de colheita (IC), e alongamento radicular (AL), em relação aos dois primeiros componentes principais.

com os piores resultados de produção de matéria seca e grãos, área foliar, e alongamento radicular.

$\mathrm{Na}$ análise discriminante, as variáveis que mostraram maior influência no agrupamento dos genótipos são: produção de grãos $(80 \%)$, produção de matéria seca $(10 \%)$ e altura da inserção de primeira vagem (10\%). Esse comportamento pode explicar o fato de as variedades IAC-9 e BR86-7396, que antes foram consideradas tolerantes ao $\mathrm{Al} \mathrm{em}$ hidroponia, terem sido colocadas em diferentes grupos. O genótipo BR86-7396 não apresentou boa produção de matéria seca e de grãos. Outro caso, que pode ser explicado pelo mesmo resultado, é o da variedade Dourados, que não se destacou como tole-

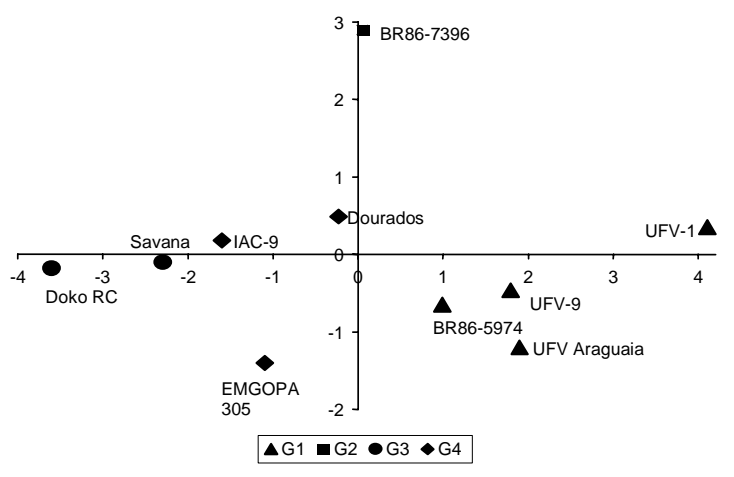

Figura 2. Dispersão dos genótipos de soja em relação aos dois primeiros componentes principais e aos grupos de similaridade.

rante na avaliação pelo alongamento radicular e foi colocada em um grupo tolerante ao $\mathrm{Al}$, pois apresentou grande produção de grãos e matéria seca.

\section{Conclusões}

1. Testes em hidroponia e em campo podem ser usados alternadamente para a seleção e o desenvolvimento de novos genótipos de soja.

2. Os genótipos apresentam variabilidade em relação à tolerância ao alumínio.

3. A identificação de grupos com maior valor agronômico possibilita a estabilidade produtiva na soja cultivada em solos com a camada subsuperficial ácida.

\section{Referências}

BENNET, R. J.; BREEN, C. M. The aluminum signal: new dimensions to mechanisms of aluminium tolerance. In: 
INTERNATIONAL SYMPOSIUM ON PLANT-SOIL INTERACTIONS AT LOW PH, 2., 1990, Beckley. Plantsoil interactions at low $\mathbf{p H}$ : proceedings. Dordrecht: Kluwer, 1991. p. 703-716.

CAMPBELL, K. A. G.; CARTER JUNIOR, T. E. Aluminum tolerance in soybean: I. Genotypic correlation and repeatability of solution culture and greenhouse screening methods. Crop Science, Madison, v. 30, p. 1049-1054, 1990.

CRUZ, C. D.; REGAZZI, A. J. Modelos biométricos aplicados ao melhoramento genético. Viçosa, MG: UFV, 1994. $390 \mathrm{p}$.

DELHAIZE, E.; RYAN, P. R. Aluminum toxicity and tolerance in plants. Plant Physiology, Rockville, v. 107, n. 2, p. 315-321, 1995.

EMBRAPA. Centro Nacional de Pesquisa de Soja (Londrina, PR). Recomendações técnicas para a cultura da soja na região central do Brasil 1998/99. Londrina, 1998. 182 p. (Documentos, 120).

FOY, C. D. Plant adaptation to acid, aluminum-toxic soils. Communications in Soil Science and Analysis, New York, v. 19, n. 12 , p. $959-987,1988$.

FRANCILLION, G.; SICARD, J. C.; SADATAILLY, P. Manuel d'utilization de LISA: logiciel intégré des systèmes agraires. Montpellier: Centre de Coopération Internationale en Recherche Agronomique pour le Développement, 1987. $145 \mathrm{p}$.

FURLANI, P. R.; CLARK, R. B. Screening sorghum for aluminum tolerance in nutrient solution. Agronomy Journal, Madison, v. 73, n. 4, p. 587-594, 1981.

GARLAND, M. L.; CAMPBELL, K. A.; CARTER JUNIOR, T. E. Aluminum tolerance in soybean: genotypic correlation and repeatability of solution culture and greenhouse screening methods. Crop Science, Madison, v. 30, p. 1049-1054, 1990.

GOLDMAN, I. L.; CARTER, T. E.; PATTERSON, R. P. A. Detrimental interaction of subsoil aluminum and drought stress on the leaf water status of soybean. Agronomy Journal, Madison, v. 81, p. 461-463, 1989.

HANSON, W. D.; KAMPRATH, E. J. Selection for aluminum tolerance in soybean based on seedling root growth. Agronomy Journal, Madison, v. 71, p. 581-586, 1979.

KINRAIDE, T. B. Identity of rhizotoxic aluminum species. Plant and Soil, Dordrecht, v. 134, n. 1, p. 167-178, 1991.
KOCHIAN, L. V. Cellular mechanisms of aluminum toxicity and resistance in plants. Annual Review of Plant Physiology and Plant Molecular Biology, Palo Alto, v. 46, p. 237-260, 1995.

MACHADO, P. L. O. de A. Considerações gerais sobre a toxicidade de alumínio nas plantas. Rio de Janeiro: Embrapa-CNPS, 1997. 22 p. (Documentos, 2).

McQUATTIE, C. J.; SCHIER, G. A. Response of red spruce seedlings to aluminum in nutrient solution: alteration in root anatomy. Canadian Journal of Forest Research, Ottawa, v. 20, p. 1001-1011, 1990.

SOUSA, D. M. G. de; LOBATO, E. Correção do solo e adubação da cultura da soja. Planaltina, DF: EmbrapaCPAC, 1996. 30 p. (Circular Técnica, 33).

SPEHAR, C. R. Aluminium tolerance of soya bean genotypes in short term experiments. Euphytica, Dordrecht, v. 76, p. 73-80, 1994a.

SPEHAR, C. R. Breeding soybeans to the low latitudes of Brazilian cerrados (savannahs). Pesquisa Agropecuária Brasileira, Brasília, v. 29, n. 8, p. 1167-1180, ago. 1994b.

SPEHAR, C. R. Comparison between hill and row plots methods on selection of soybeans for aluminium tolerance in a Brazilian savannah (cerrado) acid soil. Pesquisa Agropecuária Brasileira, Brasília, v. 33, n. 6, p. 899-904. jun. 1998.

SPEHAR, C. R. Diallel analysis for aluminium tolerance in tropical soybeans [Glycine $\max (\mathrm{L}$.) Merrill]. Theoretical and Applied Genetics, Berlin, v. 92, p. 267-272, 1996.

SPEHAR, C. R. The genetics of aluminium tolerance in soya beans Glycine max (L.) Merrill. Cambridge, Inglaterra: University of Cambridge, 1989. 123 p. Ph.D. Thesis.

SPEHAR, C. R.; GALWEY, N. W. Generation mean analysis of root growth under aluminium-stress hydroponics in the soybeans (Glycine $\max$ (L.) Merrill). Pesquisa Agropecuária Brasileira, Brasília, v. 30, n. 7, p. 963-970, jul. 1995.

SPEHAR, C. R.; MAKITA, M. Tolerância ao alumínio em plântulas de soja e sua utilização. Pesquisa Agropecuária Brasileira, Brasília, v. 29, n. 12, p. 1927-1932, dez. 1994.

VICENTE, F. M. P. Correlação entre parâmetros morfológicos obtidos em solução nutritiva, e produção de diversos cultivares de arroz (Oryza sativa L.) sob estresse de alumínio. Rio de Janeiro: UFRRJ, 1993. 103 p. Dissertação de Mestrado. 